Leszek OPYRCHAŁ

Military University of Technology (Wojskowa Akademia Techniczna)

\title{
IS MEAN TIME TO FAILURE (MTTF) EQUAL TO MEAN TIME OF LIFE FOR UNREPAIRABLE SYSTEMS?
}

\author{
Czy dla nienaprawianych systemów średni czas \\ bezawaryjnej (MTTF) pracy jest równy średniemu \\ czasowi życia?
}

\begin{abstract}
One of the most important reliability parameters is the mean time to failure (MTTF). It is widely accepted that the MTTF is equal to the mean time of life $E_{T}$. This article shows that this is not necessarily true. Although for the most commonly used statistical distributions (such as exponential, Gaussian, chi-square, Fisher-Tippett distributions) the values of MTTF and $E_{T}$ are equal, this is not the case for the log-normal distribution. Similarity, some less commonly used distributions (such as Breit-Wigner distribution) may also require calculation adjustments resulting from $M T T F \neq E_{T}$. Ignoring this discrepancy, an erroneous MTTF value can be obtained.
\end{abstract}

Keywords: reliability, mean time to failure, mean time of life

Streszczenie: Jednym z najważniejszych parametrów niezawodności jest średni czas bezawaryjnej pracy (MTTF). Powszechnie przyjmuje się, że MTTF jest równy średniemu czasowi życia E(T). Ten artykut pokazuje, że niekoniecznie jest to prawda. Chociaż dla najczęściej używanych rozkładów statystycznych (takich jak wykładniczy, Gaussa, chikwadrat, Fisher-Tippett) wartości MTTF $i E_{T}$ sa równe, to nie jest tak w przypadku rozkładu log-normalnego. Podobnie, niektóre rzadziej stosowane rozkłady (takie jak rozkład BreitWigner) moga również wymagać korekty obliczenia wynikajacej z MTTF $\neq E_{T}$. Ignorując tę rozbieżność, można uzyskać błędna wartość MTTF.

Słowa kluczowe: niezawodność, średni czas bezawaryjnej pracy, średni czas życia 


\section{Introduction}

The MTTF plays an important role in current research on system reliability. For example Izadi at al. [8] developed new nonparametric classes of distributions in terms of MTTF in age replacement, Ghazizadeh et al. [6] consider MTTF in vehicular clouds, Kattumannil and Anisha [11] developed non-parametric test for decreasing MTTF. In this work unrepairable systems was considered. However, unrepairable products are more and more common in everyday life. Therefore, it is important that the MTTF calculations for unrepairable systems are correct.

For the unrepairable systems one of the most important and most often determined parameter in the practical calculation of reliability is the mean time to failure (MTTF), which is equal to the mean of the lifetime $E_{T}$. Unrepairable system can only break once. This parameter can be calculated in the following two ways [16]. Firstly: the probability density function $f(t)$ should be estimated basis on experimental data. Then, the expected value of the mean time of life $E_{T}$ should be calculated

$$
E_{T}=\int_{0}^{\infty} \tau f(\tau) d \tau
$$

Secondly: hazard function $h(t)$ should be estimated using experimental data. Then the reliability function $R(t)$ can be calculated using the Weiner formula:

$$
R(t)=\exp \left(-\int_{0}^{t} h(\tau) d \tau\right)
$$

Knowing the reliability function $R(t)$, MTTF can be calculated

$$
\mathrm{MTTF}=\int_{0}^{\infty} R(t) d t
$$

The formulas (1-3) are well known and can be find in many handbook, for example [10].

As was mentioned, both values $E_{T}$ and MTTF are considered to be the same for unrepairable systems. However, they are defined in a different way. Thus, the question arises: are these values indeed equal?

Many handbooks and textbooks of reliability theory, such as $[1,7]$ have not addressed the equality of MTTF and $E_{T}$. In contrast, Military Handbook [12], Birolini et all. [3], Yang [17] have stated that that MTTF and $E_{T}$ are equal by definition. According to Kapur and Pecht [10] the equality of these values should be subjected to rigorous empirical and theoretical testing.

The aim of this article is to explore the equality of MTTF and $E_{T}$ values in different systems, with the focus on applications relying on different patterns of distribution. 


\section{Methods and calculations}

\subsection{General considerations}

The MTTF is defined by formula (3) and as the mean value of the time-to-failure random variable $E_{T}$ in formula (1). The probability density function $f(t)$ is related to the cumulative function by the relationship:

$$
f(t)=\frac{d F(t)}{d t} \Rightarrow F(t)=\int_{0}^{t} f(\tau) d \tau
$$

In turn, the cumulative function $F(t)$ is connected with the reliability function $R(t)$ as follow:

$$
F(t)=1-R(t)
$$

It is possible to perform the following calculations using the method of integration by parts:

$$
E_{T}=\int_{0}^{\infty} t f(t) d t=\left.t F(t)\right|_{0} ^{\infty}-\int_{0}^{\infty} F(t) d t=\left.t F(t)\right|_{0} ^{\infty}-\int_{0}^{\infty}(1-R(t)) d t,
$$

where formula (5) is included. Continuing the calculations, we get:

$$
E_{T}=\left.t F(t)\right|_{0} ^{\infty}-t_{0}^{\infty}+\int_{0}^{\infty} R(t) d t=\left.t[F(t)-1]\right|_{0} ^{\infty}+M T T F .
$$

For $E_{T}$ to be equal to MTTF, the first element $(t[F(t)-1])$ must equal zero in the limits zero and infinity. Let's calculate the limits:

$$
\lim _{t \rightarrow 0} t[F(t)-1]=0 \cdot(-1), \text { because } F(t=0)=0 .
$$

The problem arises with the limit at infinity:

$$
\lim _{t \rightarrow \infty} t[F(t)-1]
$$

because there is the indeterminate form type $\infty \cdot 0$, since

$$
\lim _{t \rightarrow \infty} t=\infty
$$


and

$$
\lim _{t \rightarrow \infty} F(t)-1=1-1=0
$$

By making a standard transformation, we get the indeterminate form $\infty / \infty$ :

$$
\lim _{t \rightarrow \infty} t[F(t)-1]=\lim _{t \rightarrow \infty} \frac{F(t)-1}{\frac{1}{t}}
$$

We apply the de l'Hospital rule and receive:

$$
\lim _{t \rightarrow \infty} \frac{f(t)}{\frac{-1}{t^{2}}}=-\lim _{t \rightarrow \infty} t^{2} f(t)
$$

As the above equation shows, for the definitions to be equivalent, $f(t)$ must be faster converged to zero than $t^{2}$ to infinity. Whether this condition is met depends on the specific form of the probability density function $f(t)$.

\subsection{Considerations for specific distribution functions}

\subsubsection{General exponential distribution}

The probability density function has the form:

$$
f(t)=\alpha t^{\beta} e^{-\theta t^{\varepsilon}},
$$

where:

$t$ - time,

$\alpha, \theta, \varepsilon$ - constant parameters, $\alpha, \theta, \varepsilon>0, \beta \geq 0$.

Depending on the parameter values $\alpha, \beta, \theta$ and $\varepsilon$, the following distributions can be described by using the above functions (tab. 1):

The exponential function is more important distribution in reliability because it describes situation wherein the hazard rate is constant. This occurs for almost every technique product in the middle of its lifetime. The exponential distribution is most often used for predicting the reliability of electronic equipment.

The chi-square distribution is currently used in reliability calculations to check the compliance hypothesis, see $[4,5,15]$. However, it cannot be excluded that one day a product will be created whose failure density function will correspond to the chi-square function 
Weibull distribution is very useful in reliability. This is a very general distribution and a wide range of different classes of engineering elements can be modeled by adjusting its parameters.

Gamma distribution is used when a certain number of partial failures must occur before the main element is damaged, see [12].

Table 1

Types of statistical distributions depending on the value of the parameters of general exponential distributions

\begin{tabular}{|c|c|c|}
\hline distribution & parameter values & formula \\
\hline exponential & $\alpha=\lambda, \beta=0, \theta=\lambda, \varepsilon=1$ & $f(t)=\lambda e^{-\lambda t}$ \\
\hline chi-square & $\alpha=\frac{\left(\frac{1}{2}\right)^{\frac{N}{2}}}{\Gamma\left(\frac{N}{2}\right)}, \beta=\frac{N}{2}-1, \theta=\frac{1}{2}$ & $f(t)=\frac{\frac{1}{2}\left(\frac{t}{2}\right)^{\frac{N}{2}-1}}{\Gamma\left(\frac{N}{2}\right)} e^{\frac{-1}{2} t}$ \\
\hline Weibull & $N-$ natural number, $N \geq 2$ & $f(t)=\frac{\eta}{\sigma}\left(\frac{t}{\sigma}\right)^{\eta-1} e^{-\left(\frac{t}{\sigma}\right)^{\eta}}$ \\
\hline gamma & $\alpha, \eta-\frac{\eta}{\sigma^{\eta}}, \beta=\eta-1, \theta=\frac{1}{\sigma^{\eta}}, \varepsilon=\eta$ & \\
\hline & $\alpha=\frac{\eta}{\sigma^{\eta}}, \beta=\eta-1, \theta=\frac{1}{\sigma^{\eta}}, \varepsilon=\eta$ & $f(t)=\frac{\lambda^{\eta}}{\Gamma(\eta)} t^{\eta-1} e^{-\lambda t}$ \\
\hline
\end{tabular}

For the general exponential distribution the following limit is searched:

$$
\lim _{t \rightarrow \infty} t^{2} f(t)=\lim _{t \rightarrow \infty} \alpha t^{\beta+2} e^{-\theta t^{\varepsilon}}=\lim _{t \rightarrow \infty} \frac{\alpha t^{\beta+2}}{e^{\theta t^{\varepsilon}}} .
$$

Applying the de l'Hospital rule we get:

$$
\lim _{t \rightarrow \infty} \frac{\alpha t^{\beta+2}}{e^{\theta t^{\varepsilon}}}=\lim _{t \rightarrow \infty} \frac{\alpha(\beta+2) t^{\beta+1}}{\theta \varepsilon t^{\varepsilon-1} e^{\theta t^{\varepsilon}}}=\lim _{t \rightarrow \infty} \frac{\alpha(\beta+2)}{\theta \varepsilon} \frac{t^{\beta+2-\varepsilon}}{e^{\theta t^{\varepsilon}}} .
$$

The constant factor $\frac{\alpha(\beta+2)}{\theta \cdot \varepsilon}$ does not affect the limit. After performing the differentiation, in the numerator instead of $t^{\beta+2}$ a factor $t^{\beta+2-\varepsilon}$ appeared and the exponent has been reduced by the value of $\varepsilon$. If it is positive, we will again apply the de l'Hospital rule until the exponent is a negative number. Then the numerator will be convergent to zero, and the denominator to infinity, that is, the whole fraction will be convergent to zero. 


\subsubsection{Gaussian distribution}

In reliability, Gaussian distribution is mainly used for two purposes. First for analyzing items that show failure due to wear, such as mechanical devices. Secondly is the analysis of manufactured items and their ability to meet specifications, i.e. for quality control purposes [7].

The probability density function is:

$$
f(t)=\frac{1}{\sigma \sqrt{2 \pi}} e^{\frac{-1}{2}\left(\frac{t-\mu}{\sigma}\right)^{2}}
$$

where:

$t$ - time,

$\sigma, \mu$-constant parameters, positive.

For Gaussian distribution the limit is calculated:

$$
\lim _{t \rightarrow \infty} t^{2} f(t)=\lim _{t \rightarrow \infty} t^{2} \frac{1}{\sigma \sqrt{2 \pi}} e^{\frac{-1}{2}\left(\frac{t-\mu}{\sigma}\right)^{2}}=\lim _{t \rightarrow \infty} \frac{\sigma \sqrt{2 \pi} t^{2}}{e^{\frac{1}{2}\left(\frac{t-\mu}{\sigma}\right)^{2}}}
$$

After applying de l'Hospital rule, we receive:

$$
\lim _{t \rightarrow \infty} t^{2} f(t)=\lim _{t \rightarrow \infty} \frac{2 t}{\sqrt{2 \pi} \cdot \frac{t-\mu}{\sigma} \cdot e^{\frac{1}{2}\left(\frac{t-\mu}{\sigma}\right)^{2}}}
$$

This is the indeterminate form type $\infty / \infty$. Therefore, the de l'Hospital rule must be applied twice. The result is:

$$
\lim _{t \rightarrow \infty} \frac{2 \sigma^{5} \sqrt{2 \pi}}{e^{\frac{1}{2}\left(\frac{t-\mu}{\sigma}\right)^{2}}\left[\mu^{2}+\sigma^{2}+t(t-2 \mu)\right]}=0
$$

because both

$$
\lim _{t \rightarrow \infty} e^{\frac{1}{2}\left(\frac{t-\mu}{\sigma}\right)^{2}}=\infty
$$

as well

$$
\lim _{t \rightarrow \infty}\left[\mu^{2}+\sigma^{2}+t(t-2 \mu)\right]=\infty
$$




\subsubsection{Extreme value distribution}

Extreme value distribution is very useful to describing the probabilistic nature of extreme value of some phenomena in the time, both larges or smallest, see: $[9,13]$.

The probability density function is:

$$
f(t)=\frac{1}{\sigma} e^{\frac{t-\mu}{\sigma}-e^{\frac{t-\mu}{\sigma}}}
$$

where:

$t-$ time,

$\mu, \sigma>0$ - constant parameters, positive.

The limit is calculated as:

$$
\lim _{t \rightarrow \infty} t^{2} f(t)=\lim _{t \rightarrow \infty} t^{2} \frac{1}{\sigma} e^{\frac{t-\mu}{\sigma}-e^{\frac{t-\mu}{\sigma}}}=\lim _{t \rightarrow \infty} \frac{t^{2}}{\sigma e^{\frac{-t+\mu}{\sigma}+e^{\frac{t-\mu}{\sigma}}}}
$$

The de l'Hospital rule is applied twice

$$
\lim _{t \rightarrow \infty} \frac{2 t}{e^{e^{\frac{\mu-t}{\sigma}}-\frac{\mu}{\sigma}\left(e^{\frac{t}{\sigma}}-e^{\frac{\mu}{\sigma}}\right)}}=\lim _{t \rightarrow \infty} \frac{2 \sigma}{e^{e^{\frac{\mu-t}{\sigma}}-\frac{t+\mu}{\sigma}} \cdot\left(-e^{\frac{t+\mu}{\sigma}}+e^{\frac{2 t}{\sigma}}+e^{\frac{2 \mu}{\sigma}}\right)}=0
$$

because

$$
\lim _{t \rightarrow \infty} e^{e^{\frac{\mu-t}{\sigma}}-\frac{t+\mu}{\sigma}} \cdot\left(-e^{\frac{t+\mu}{\sigma}}+e^{\frac{2 t}{\sigma}}+e^{\frac{2 \mu}{\sigma}}\right)=\infty
$$

\subsubsection{Log-normal distribution}

Logarithmic distribution is mainly used in semiconductor reliability analysis and for fatigue life analysis some types of mechanical components [12]. The probability density function is

$$
f(t)=\frac{1}{\sigma t \sqrt{2 \pi}} e^{\frac{-1}{2}\left(\frac{\ln (t)-\mu}{\sigma}\right)^{2}}
$$

where:

$t$ - time,

$\sigma, \mu-$ constant parameters, positive. 
The limit is calculated:

$$
\lim _{t \rightarrow \infty} t^{2} f(t)=\lim _{t \rightarrow \infty} \frac{t^{2}}{\sigma t \sqrt{2 \pi} e^{\frac{1}{2}\left(\frac{\ln (t)-\mu}{\sigma}\right)^{2}}}=\frac{\lim _{t \rightarrow \infty} t}{\sigma \sqrt{2 \pi} e^{\frac{1}{2}\left(\frac{\ln (t)-\mu}{\sigma}\right)^{2}}}
$$

The de l'Hospital rule is applied

$$
\lim _{t \rightarrow \infty} \frac{1}{\frac{\sqrt{2 \pi}(\ln (t)-\mu) e^{\frac{1}{2}\left(\frac{\ln (t)-\mu}{\sigma}\right)^{2}}}{\sigma^{2} t}}=\lim _{t \rightarrow \infty} \frac{\sigma^{2} t}{\sqrt{2 \pi}(\ln (t)-\mu) e^{\frac{1}{2}\left(\frac{\ln (t)-\mu}{\sigma}\right)^{2}}}
$$

It should be noted that the variable $t$ remained in the numerator. This means that it is not possible to calculate this limit using the method described in the section 2.1., because after performing the differentiation of the $\ln (t)$ function, the variable $t$ will always appear in the numerator.

\subsubsection{Breit-Wigner distribution}

The Breit-Wigner distribution is also called the Cauchy distribution. It is used in the analysis of data that contains outliers. Also, if the extremes are true data values, Cauchy distribution seems to be the most appropriate model, see [2]. The probability density of the Breit-Wigner distribution is:

$$
f(t)=\frac{1}{\pi \sigma\left[1+\left(\frac{t-\mu}{\sigma}\right)^{2}\right]}
$$

where:

$t$ - time,

$\sigma, \mu$-constant parameters, positive.

Calculation of the limit:

$$
\lim _{t \rightarrow \infty} t^{2} f(t)=\lim _{t \rightarrow \infty} \frac{t^{2}}{\pi \sigma\left[1+\left(\frac{t-\mu}{\sigma}\right)^{2}\right]}
$$

There is applied the d'Hospital rule twice:

$$
\lim _{t \rightarrow \infty} \frac{2 t}{2 \pi \sigma\left(\frac{t-\mu}{\sigma}\right)}=\frac{1}{\pi}
$$




\section{Results}

The results of the calculations are presented in the tab. 2. It includes: name of the statistical distribution and statement if the MTTF is can be considered as identical to $\mathrm{E}_{\mathrm{T}}$. The calculations were made for the most common statistical distributions in practice. Other distributions have not been studied.

Table 2

The results of the calculations the equality of mean time to failure (MTTF) and the expected value $E_{T}$ of the distribution. Yes - means that the values defined by the formula (1) and (2) are equal. Further research should be carried out to determine the equality of MTTF and $\mathrm{E}_{\mathrm{T}}$ values for the Log-normal distribution.

\begin{tabular}{||c|c|}
\hline Distribution & MTTF $=E_{T}$ \\
\hline \hline Exponential & yes \\
\hline Chi-Square & yes \\
\hline Weibull & yes \\
\hline Gamma & yes \\
\hline Gaussian & yes \\
\hline Fischer-Tippet & yes \\
\hline Log-normal & indeterminate \\
\hline Breit-Wigner & no \\
\hline
\end{tabular}

\section{Conclusions}

The equality of MTTF and $\mathrm{E}_{\mathrm{T}}$ was found in six out of eight cases of the statistical distributions that were examined. This means that MTTF and $E_{T}$ can be used interchangeably in practical calculations utilizing Exponential, Chi-square, Weibull, Gamma, Gaussian, Exstremly value, distributions. In the case of Breit-Wigner distribution, such equivalence does not exist, because there is no expected value of this distribution. The equality of MTTF and $E_{T}$ values for the Log-normal distribution has not been confirmed. The expected value of the Log-normal distribution, which according to James [9] is:

$$
\mathrm{E}_{\mathrm{T}}=e^{\left(\mu-\frac{1}{2} \sigma\right)}
$$

does not need to be equal to MTTF. The Log-normal distribution is often used in practical calculations [14]. Therefore, this problem requires further research. The same as examining the equality of MTTF and $E_{T}$ for other, less popular statistical distributions. 


\section{References}

1. Ayyub B., McCuen R.H.: Probability, Statistics, \& Reliability for Engineers. CRC Press, New York 1997.

2. Bain L.J.: Statistical Analysis of Reliability and Life-Testing Models. Theo ry and Methods. New York - Basel - Hong Kong 1991.

3. Birolini A.: Reliability engineering. Theory and practice. Springer-Verlag, Berlin 2007.

4. Ellerman P.: Calculating Chi-squared (X2) for Reliability Equations. 2012, available from: https://www.microsemi.com/document-portal/doc_view/124039-calculatingchi-squared-x2-for-reliability-equations.

5. Feinberg A.: Chi-Squared Accelerated Reliability Growth model. Proceedings Annual Reliability and Maintainability Symposium (RAMS), Orlando, FL, 2013, DOI 10.1109/RAMS.2013.6517750.

6. Ghazizadeh P., Florin R., Zadeh A.G., Olairu S.: Reasoning about mean time to failure in vehicular clouds. IEE Transactions on Intelligent Transportation Systems, Vol. 17, No. 3, 2016.

7. Ireson W.G, Coombs C.F. (eds.): Handbook of reliability engineering and management. McGraw-Hill, New York 1966.

8. Izadi M., Sharafi M., Khaledi B-E.: New nonparametric classes of distributions in term of mean time to failure in age replacement. Journal of Applied Probability, 55(4), 2018, DOI 10.1017/jpr.2018.82.

9. James F.: Statistical methods in experimental physics. World Scientific, New Jersey 2006.

10. Kapur K., Pecht M.: Reliability engineering. John Wiley \& Sons, New Jersey 2014.

11. Kattumannil S.K., Anisha P.: A simple non-parametric test for decreasing mean time to failure. Statistical Papers, 2019, DOI 10.1007/s00362-016-0827-y.

12. Military Handbook, Electronic Reliability Design Handbook, MIL-HDBK-338 Rev. B, 1998, available from: https://www.navsea.navy.mil/Portals/103/Documents/ NSWC_Crane/SD-18/Test\%20Methods/MILHDBK338B.pdf.

13. Nowak A., Collins S.: Reliability of structures. CRC Press, Taylor \& Francis Group, London - New York 2013.

14. Soong T.T.: Fundamentals f probability and statistics for engineers. John Wiley \& Sons, New Jersey 2004.

15. Uprety I., Patrai K.: Fuzzy Reliability Estimation Using Chi-Squared Distribution. 3rd International Conference on Soft Computing \& Machine Intelligence (ISCMI), Dubai 2016, DOI 10.1109/ISCMI.2016.53.

16. Watson G.S., Leadbetter M.R.: Hazard Analysis. I, Biometrika, Vol. 51, No. 1/2, 1964.

17. Yang G.: Life cycle reliability engineering. John Wiley \& Sons, New Jersey 2007. 